\title{
A Study on the Transition of Copper Oxide by the Incorporation of Nitrogen
}

\author{
Song-Yi Ahn ${ }^{1}$, Kyung Park ${ }^{2}$, Daehwan Choi ${ }^{3}$, Jozeph Park ${ }^{4, *}$, Yong Joo Kim ${ }^{5, * \mathbb{C}}$ and \\ Hyun-Suk Kim ${ }^{1, *}$ \\ 1 Department of Materials Science and Engineering, Chungnam National University, Daejeon 34134, Korea; \\ dksthdd1123@naver.com \\ 2 Semiconductor Process Laboratory, WONIK IPS, Gyeonggi-do 17709, Korea; kyungpark@yonsei.ac.kr \\ 3 School of Integrated Technology, Yonsei University, Incheon 21983, Korea; maximum@yonsei.ac.kr \\ 4 Department of Material Science and Engineering, Korea Advanced Institute of Science and Technology, \\ Daejeon 34141, Korea \\ 5 Biosystems Machinery Engineering, Chungnam National University, Daejeon 34134, Korea \\ * Correspondence: jozeph.park@gmail.com (J.P.); babina@cnu.ac.kr (Y.J.K.); khs3297@cnu.ac.kr (H.-S.K.)
}

Received: 4 September 2019; Accepted: 27 September 2019; Published: 29 September 2019

\begin{abstract}
In the present study, the effects of nitrogen incorporation on the transition of a p-type copper oxide semiconductor are investigated. The properties of sputtered copper oxide and nitrogen-incorporated copper oxide are evaluated and compared at various nitrogen gas flow rates. The results indicate that the addition of nitrogen results in an increased optical bandgap, accompanied by significantly reduced tail states compared to pristine copper oxide. In addition, $\mathrm{X}$-ray diffraction and X-ray photoelectron spectroscopy reveal that the incorporation of nitrogen stimulates the transition from copper (II) oxide to copper (I) oxide.
\end{abstract}

Keywords: nitrogen incorporation; $\mathrm{CuON}$; p-type oxide semiconductor; reactive sputtering; thin-film transistors

\section{Introduction}

Recently, thin-film transistors (TFTs) based on metal oxide semiconductors such as In-Ga-Zn-O (IGZO) have attracted considerable attention for pixel-switching devices in flat-panel displays owing to their relatively high performance and stability compared to amorphous silicon (a-Si) [1-3]. Commercial products incorporating TFT backplanes based on n-type IGZO are already available in the market. On the other hand, relatively few reports are available on p-type oxide semiconductors.

Candidate p-type oxide semiconductors include copper oxide $\left(\mathrm{CuO}_{\mathrm{x}}\right)$, tin oxide $\left(\mathrm{SnO}_{\mathrm{x}}\right)$, and nickel oxide $\left(\mathrm{NiO}_{\mathrm{x}}\right)$ [3-7]. Among them, copper oxide is a non-toxic, cost-effective material that may be deposited by various techniques such as sputtering, chemical vapor deposition, and even the sol-gel method [8-11]. As a transition metal, copper oxide may exhibit two different phases, namely cupric oxide (copper (II) oxide, $\mathrm{CuO}$ ) and cuprous oxide (copper (I) oxide, $\mathrm{Cu}_{2} \mathrm{O}$ ). The monoclinic $\mathrm{CuO}$ and cubic $\mathrm{Cu}_{2} \mathrm{O}$ have optical bandgap energy values around 1.9-2.1 eV and 2.1-2.6 eV, respectively $[12,13]$. Generally, most amorphous oxide semiconductors have significantly low hole mobility compared to electron mobility, because of the localized valence band (VB) states resulting from highly directional $\mathrm{O}$ $2 p$ orbitals. However, copper oxide exhibits a quite different orbital configuration of the VB states. The $\mathrm{Cu} 3 \mathrm{~d}$ and $\mathrm{O} 2 \mathrm{p}$ orbitals are located at nearly the same energy level near the valence band maximum (VBM), and are fully occupied by hybridization. Such a configuration forms less-localized VBM states, creating relatively fast pathways for hole carriers [14-16]. Charge transport in copper oxide occurs mainly via charged $\mathrm{Cu}$ vacancies, which generate acceptor levels near $0.3 \mathrm{eV}$ above the VBM [17,18]. To 
obtain high-performance, copper oxide-based p-type thin-film transistors, the former studies generally reported on the effect of annealing temperature, oxygen flow ratio during growth, and external dopant concentration [19-22]. Especially, the incorporation of nitrogen was observed to improve the electrical properties of copper oxide, yet the exact mechanism was not elucidated.

In the present work, the properties of $\mathrm{CuO}$ and $\mathrm{N}$-incorporated $\mathrm{CuO}(\mathrm{CuON})$ thin films and the related TFTs are investigated. The results indicate that $\mathrm{CuON}$ has significantly decreased tail states compared to pristine $\mathrm{CuO}$, as well as increased optical bandgap energy. Moreover, $\mathrm{X}$-ray diffraction (XRD) and X-ray photoelectron spectroscopy (XPS) examinations reveal that the nitrogen incorporation in copper oxide stimulates the transition from copper (II) oxide to copper (I) oxide.

\section{Experimental Section}

$\mathrm{Cu}_{\mathrm{x}} \mathrm{O}$ and $\mathrm{CuON}$ thin films were deposited by reactive radio frequency (RF) magnetron sputtering at room temperature with a 3-inch diameter metal $\mathrm{Cu}$ target $(99.99 \%)$. The applied RF power and gas mixing ratio of $\mathrm{Ar} / \mathrm{O}_{2}$ were fixed at $80 \mathrm{~W}$ and 10:10 $(\mathrm{sccm} / \mathrm{sccm})$, respectively. The nitrogen gas flow rates were varied from 0 to $50 \mathrm{sccm}$. The working pressure values also varied from 7 to $22 \mathrm{mTorr}$ as the amount of nitrogen gas was increased. The microstructures of $\mathrm{Cu}_{\mathrm{x}} \mathrm{O}$ and $\mathrm{CuON}$ thin films were analyzed by grazing incidence angle $\mathrm{X}$-ray diffraction (GIAXRD) using a $\mathrm{Cu} k \alpha$ radiation (D8 DISCOVER, Bruker AXS, Billerica, MA, USA). The surface morphologies were studied by atomic force microscopy (AFM). The chemical bonding states of nitrogen and oxygen components were examined by X-ray photoelectron spectroscopy (XPS) (K-ALPHA ESCA SYSTEM, ThermoFisher Scientificz, Waltham, MA, USA). The optical transmittance and bandgap values were extracted using a Transmittance UV-vis Spectrometer (S-3100, SCINCO, Seoul, Korea) in the range of 200 to $1000 \mathrm{~nm}$. Hall measurements were also carried out to observe the electrical characteristics of thin films (HMS-5500, ECOPIA, Gyeonggi-do, Korea).

$\mathrm{Cu}_{\mathrm{x}} \mathrm{O}$ and $\mathrm{CuON}$ TFTs with bottom-gated structures were fabricated on highly doped p-type $\mathrm{Si}$ substrates with thermally grown 100-nm thick $\mathrm{SiO}_{2}$ gate dielectrics. After depositing the $\mathrm{Cu}_{\mathrm{x}} \mathrm{O}$ or $\mathrm{CuON}$ active layers, post-annealing was conducted at $300{ }^{\circ} \mathrm{C}$ for $2 \mathrm{~h}$ in a vacuum ambient by a rapid thermal annealing system (RTA). Then, the source-drain electrodes were formed using a shadow mask, by depositing a 100-nm thick nickel (Ni) film by thermal evaporation. The width and length of the resulting devices were $800 \mu \mathrm{m}$ and $200 \mu \mathrm{m}$, respectively. The transfer characteristics were analyzed using an HP 4156B semiconductor parameter analyzer (HEWLETT PACKARD, CA, USA) in the dark under ambient conditions.

\section{Results and Discussions}

The XRD patterns of pristine $\mathrm{Cu}_{\mathrm{x}} \mathrm{O}$ exhibit intense (-111) and (111) peaks of a monoclinic structure at $2 \theta=36$ and $38^{\circ}$, respectively in Figure 1a. After annealing, the same peaks persist, as shown in Figure 1b. Similarly, the as-deposited $\mathrm{CuON}$ film also exhibits identical peaks; however, the $(-111)$ peak is more intense compared to those of the as-deposited and annealed $\mathrm{Cu}_{\mathrm{x}} \mathrm{O}$ films (Figure 1c). On the other hand, the annealed $\mathrm{CuON}$ film exhibits a quite different structure. The corresponding diffractogram in Figure 1d exhibits the (111) and (200) peaks of $\mathrm{Cu}_{2} \mathrm{O}\left(\mathrm{N}_{2} 50 \mathrm{sccm}\right)$. No apparent reaction between copper and nitrogen seems to have taken place, since even at relatively high nitrogen gas flow rates, no peaks related to compounds such as $\mathrm{Cu}_{3} \mathrm{~N}$ are detected. At this point, it is suggested that nitrogen inhibits the oxidation of $\mathrm{CuO}$ and promotes the formation of the $\mathrm{Cu}_{2} \mathrm{O}$ phase. When nitrogen is incorporated in the plasma environment, nitrogen may play a role of removing oxygen gas as follows: $1 / 2 \mathrm{O}_{2}+\mathrm{N}_{2} \rightarrow \mathrm{N}_{2} \mathrm{O}$ or $\mathrm{O}_{2}+\mathrm{N}_{2} \rightarrow 2 \mathrm{NO}$. Figure 2 shows the AFM surface morphologies of $\mathrm{Cu}_{\mathrm{x}} \mathrm{O}$ and $\mathrm{CuON}$ layers. In the $\mathrm{Cu}_{\mathrm{x}} \mathrm{O}$ film, the root mean square (RMS) surface roughness is $0.83 \mathrm{~nm}$, while $\mathrm{CuON}$ films grown with different nitrogen gas flow rates all exhibit relatively smooth surfaces with RMS roughness values no greater than $0.57 \mathrm{~nm}$. 


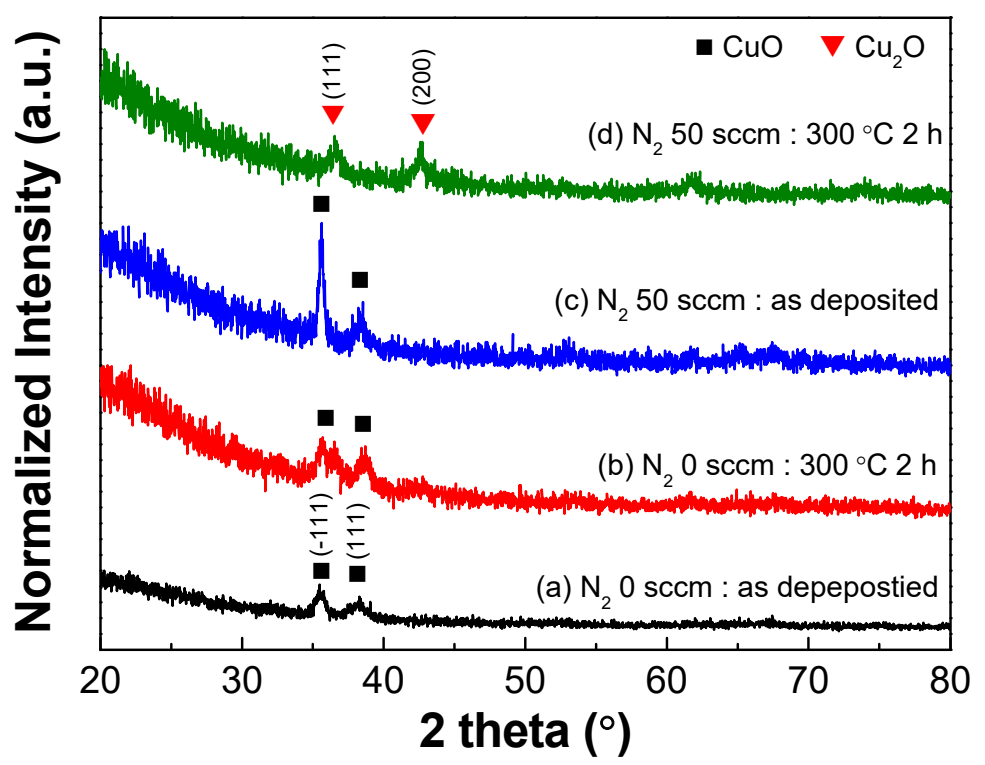

Figure 1. XRD patterns of $\mathrm{Cu}_{\mathrm{x}} \mathrm{O}$ and $\mathrm{CuON}$ films. (a) as-deposited $\mathrm{Cu}_{\mathrm{x}} \mathrm{O}$, (b) annealed $\mathrm{Cu}_{\mathrm{x}} \mathrm{O}$, (c) as-deposited $\mathrm{CuON}$, and (d) annealed $\mathrm{CuON}$.

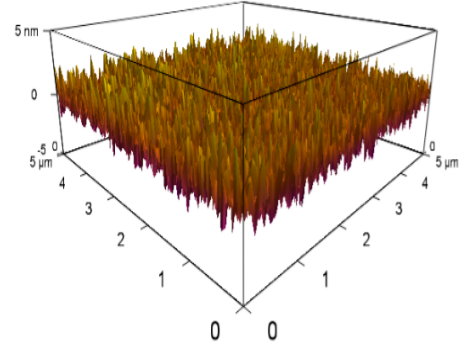

(a) RMS: $0.83 \mathrm{~nm}$

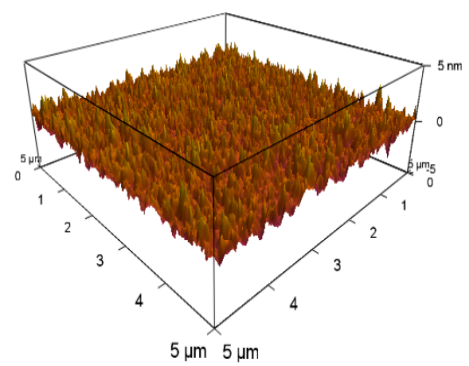

(c) RMS: $0.57 \mathrm{~nm}$
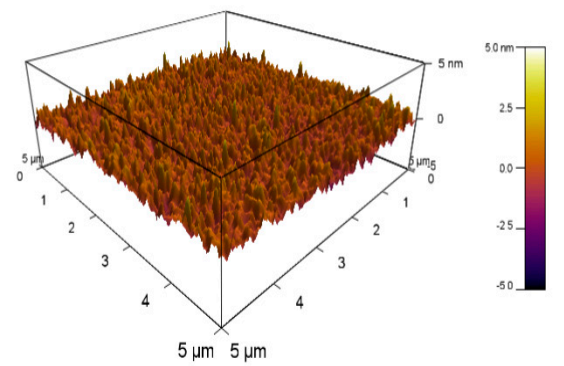

(b) RMS: $0.50 \mathrm{~nm}$

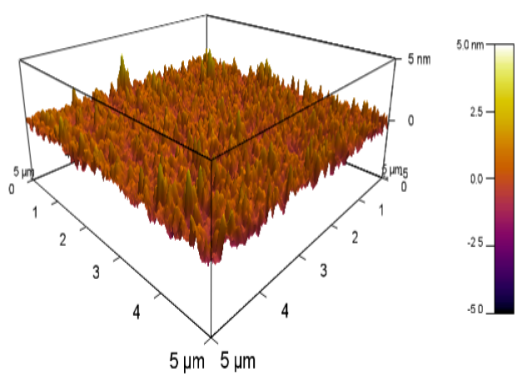

(d) RMS: $0.51 \mathrm{~nm}$

Figure 2. Atomic force microscope images of films grown with (a) $\mathrm{N}_{2} 0 \mathrm{sccm}$, (b) $\mathrm{N}_{2} 10 \mathrm{sccm}$, (c) $\mathrm{N}_{2} 20$ sccm, and (d) $\mathrm{N}_{2} 50 \mathrm{sccm}$.

The optical transmittance curves of $\mathrm{Cu}_{\mathrm{x}} \mathrm{O}$ and $\mathrm{CuON}$ layers were collected over a wavelength range of 200-1000 nm, as shown in Figure 3a. Figure 3b shows how Tauc's law is used to extract the optical bandgap values of 1.99 and $2.49 \mathrm{eV}$ for $\mathrm{Cu}_{\mathrm{x}} \mathrm{O}$ and $\mathrm{CuON}$, respectively. After annealing, the optical bandgap values increased slightly up to 2.00 and $2.59 \mathrm{eV}$ for $\mathrm{Cu}_{\mathrm{x}} \mathrm{O}$ and $\mathrm{CuON}$, respectively. Therefore, the incorporation of nitrogen appears to affect the optical bandgap. Figure $3 c$ shows the absorption coefficient spectra as a function of photon energy in the $\mathrm{Cu}_{\mathrm{x}} \mathrm{O}$ and $\mathrm{CuON}$ films. The tail state extending in the bandgap is called the Urbach tail, and its slope reflects the number of localized trap states. The small slope of the Urbach tail suggests that it has a large amount of localized trap state 
in the optical bandgap [20]. As the absorption spectra of pristine and annealed films in the subgap region show, $\mathrm{CuON}$ (i.e., the region of the green circle marked with $\mathrm{E}_{\mathrm{g}}<2.59 \mathrm{eV}$ ) layers exhibit smaller subgap defect absorption than $\mathrm{Cu}_{\mathrm{x}} \mathrm{O}$ (i.e., the region of the blue circle marked with $\mathrm{E}_{\mathrm{g}}<2.00 \mathrm{eV}$ ) films. At this point, it is highly likely that the presence of nitrogen results in decreased tail states.

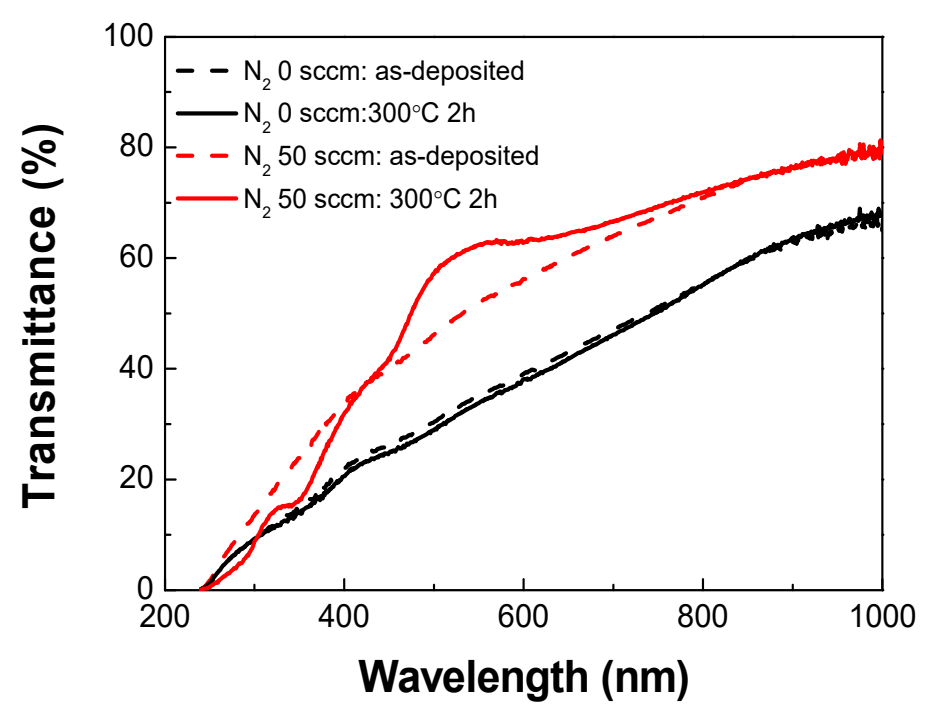

(a)

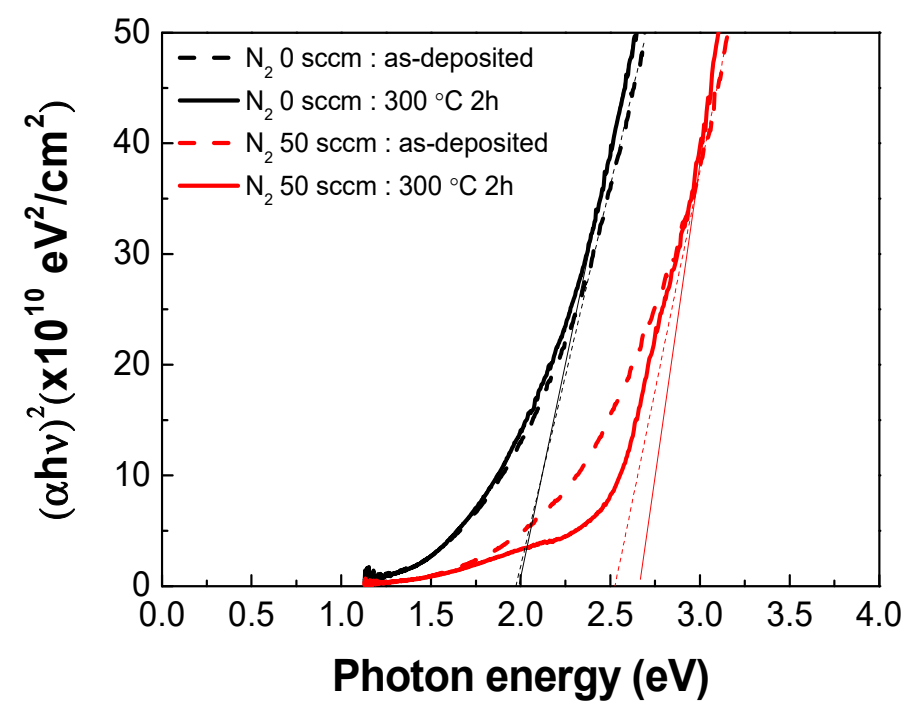

(b)

Figure 3. Cont. 


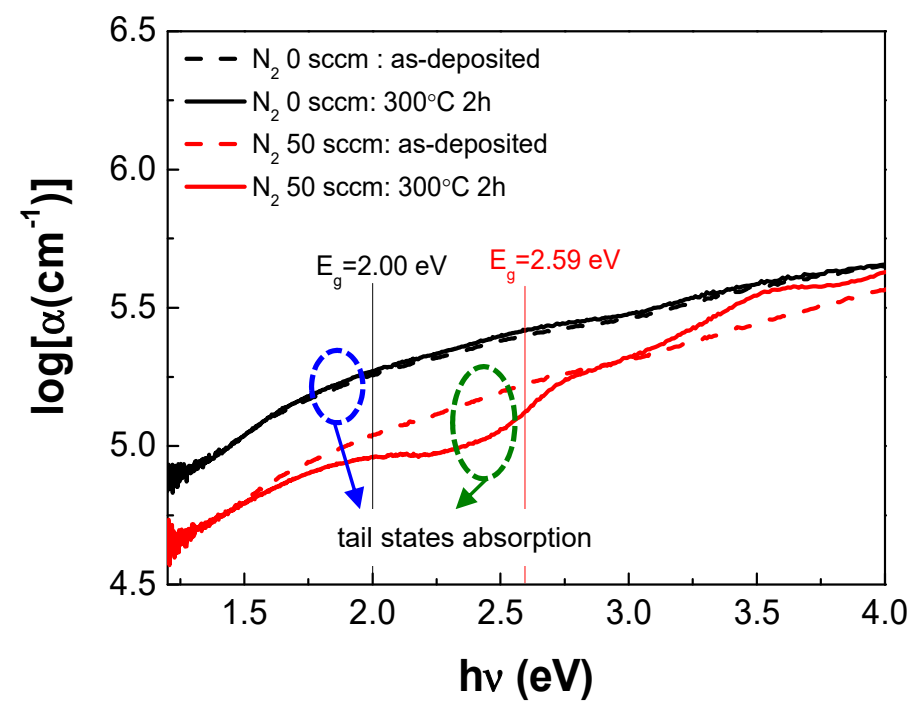

(c)

Figure 3. (a) Transmittance spectra of as-deposited and post-annealed films grown under $\mathrm{N}_{2} 0$ and 50 sccm, respectively. (b) Optical bandgap with respect to $\mathrm{N}_{2}$ flow rates using Tauc's plot. (c) The tail state absorption with respect to $\mathrm{N}_{2}$ flow rates.

XPS analyses were performed to observe the chemical bond properties in the films. The peak positions were calibrated using the $\mathrm{C} 1$ s peak, of which the standard binding energy is about $284.5 \mathrm{eV}$. Figure 4 shows the $\mathrm{Cu} 2 \mathrm{p}_{1 / 2}$ spectra of annealed $\mathrm{Cu}_{\mathrm{x}} \mathrm{O}$ and $\mathrm{CuON}$. Both as-deposited $\mathrm{Cu}_{\mathrm{x}} \mathrm{O}$ and $\mathrm{CuON}$ thin films exhibit shoulder peaks around $954 \mathrm{eV}$ and satellite peaks near $962 \mathrm{eV}$. Such satellite and shoulder peaks originate from copper (II) oxide [22-24]. The intensities of the satellite and shoulder peaks in $\mathrm{CuON}$ decrease largely after annealing, which strongly suggests that some transition from monoclinic $\mathrm{CuO}$ to cubic $\mathrm{Cu}_{2} \mathrm{O}$ has occurred. Such results are also in agreement with the XRD results shown in Figure 1. Figure 5a-d shows the $\mathrm{O} 1$ s peak spectra of the $\mathrm{Cu}_{\mathrm{x}} \mathrm{O}$ and $\mathrm{CuON}$ films. The peaks were resolved into two sub-peaks from metal oxygen bonds $(\mathrm{M}-\mathrm{O})$ and oxygen-related defects bond such as oxygen deficient sites $\left(\mathrm{V}_{\mathrm{O}}\right)$ and contamination species $\left(\mathrm{OH}^{-}\right)$. Generally, it is well-known that the $\mathrm{M}-\mathrm{O}$, oxygen-related defects peaks in metal oxides are located near $530.6 \mathrm{eV}$ and $531.9 \mathrm{eV}$, respectively $[19,25,26]$. In $\mathrm{Cu}_{\mathrm{x}} \mathrm{O}$ films, the $\mathrm{O} 1$ s sub-peak spectra did not change much after annealing, which suggests that no transition has taken place. However, the addition of nitrogen results in an increased oxygen-related defects peak portion from $20.9 \%$ to $34.9 \%$, as is observed in pristine $\mathrm{Cu}_{\mathrm{x}} \mathrm{O}$ and $\mathrm{CuON}$, respectively. It suggests that nitrogen incorporation may disturb $\mathrm{Cu}-\mathrm{O}$ bonds and increase disordering or O-related defect density. However, as the $\mathrm{CuON}$ layers are annealed, the oxygen-related defects peak portion decreases considerably from $34.9 \%$ to $17.7 \%$. While the migration of nitrogen forming $\mathrm{Cu}-\mathrm{N}$ bonds may have contributed to the decrease in the intensity of the oxygen-related defects, the transition from $\mathrm{CuO}$ to $\mathrm{Cu}_{2} \mathrm{O}$ is also a probable factor. Figure $5 \mathrm{e}$ shows the $\mathrm{N} 1 \mathrm{~s}$ peak of the pristine and annealed $\mathrm{CuON}$ thin films. The peak at $398.08 \mathrm{eV}$ indicates the presence of $\mathrm{Cu}-\mathrm{N}$ bonds [20]. In contrast, $\mathrm{Cu}-\mathrm{N}$ bonds are not detected in pristine $\mathrm{CuON}$, which implies that the incorporated nitrogen atoms are most likely to exist in the form of weakly bonded interstitials. 
(a)

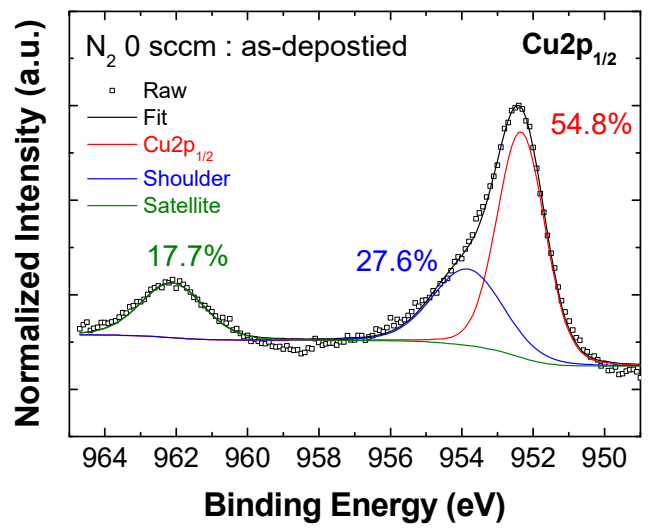

(c)

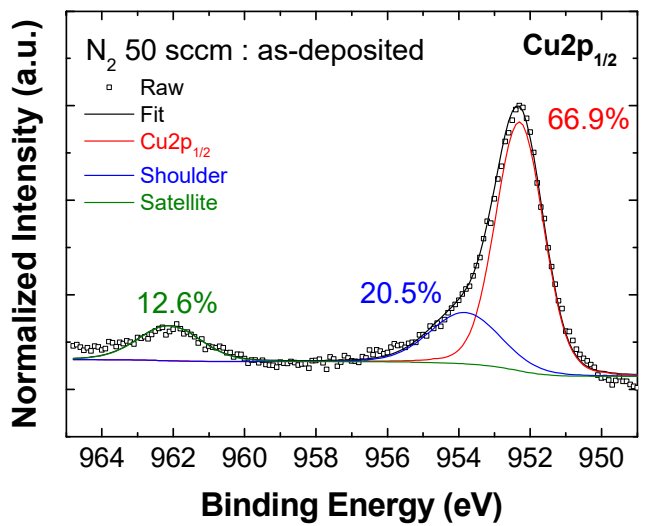

(b)

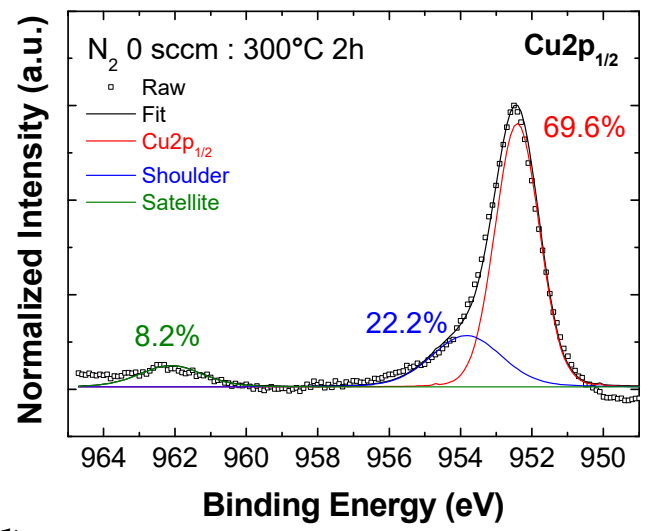

(d)

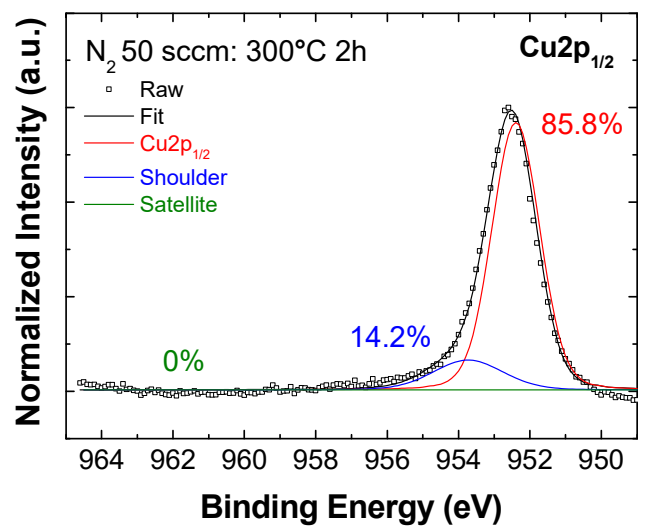

Figure 4. X-ray photoelectron spectroscopy (XPS) $\mathrm{Cu} 2 \mathrm{p}_{1 / 2}$ peaks of (a) as-deposited $\mathrm{Cu}_{x} \mathrm{O},(\mathbf{b})$ annealed $\mathrm{Cu}_{\mathrm{x}} \mathrm{O}$, (c) as-deposited $\mathrm{CuON}$, and (d) annealed $\mathrm{CuON}$.

The relative atomic compositions of $\mathrm{Cu}_{\mathrm{x}} \mathrm{O}$ and $\mathrm{CuON}$ films are indicated in Table 1. Only the annealed $\mathrm{CuON}$ film exhibits a $\mathrm{Cu}: \mathrm{O}$ composion ratio of 2:1, while the other samples exhibit $\mathrm{Cu}: \mathrm{O}$ ratios near 1:1. In accordance with the XRD results, it may be concluded that the incorporated nitrogen promotes the transition from $\mathrm{CuO}$ to $\mathrm{Cu}_{2} \mathrm{O}$ after thermal treatment.

Table 1. The atomic compositions of $\mathrm{Cu}_{\mathrm{x}} \mathrm{O}$ and $\mathrm{CuON}$ films obtained by XPS analysis.

\begin{tabular}{cccc}
\hline Experimental Condition & $\mathbf{C u}$ & $\mathbf{O}$ & $\mathbf{N}$ \\
\hline $\mathbf{N}_{\mathbf{2}} \mathbf{0 :}$ as dep & 48.98 & 51.01 & - \\
$\mathbf{N}_{\mathbf{2}} \mathbf{0 :} \mathbf{3 0 0}{ }^{\circ} \mathbf{C} \mathbf{2} \mathbf{h}$ & 57.66 & 41.88 & 0.44 \\
$\mathbf{N}_{\mathbf{2}} \mathbf{5 0 :}$ as dep & 50.52 & 49.47 & - \\
$\mathbf{N}_{\mathbf{2}} \mathbf{5 0}: \mathbf{3 0 0}{ }^{\circ} \mathbf{C} \mathbf{2} \mathbf{h}$ & 69.77 & 28.74 & 1.48 \\
\hline
\end{tabular}




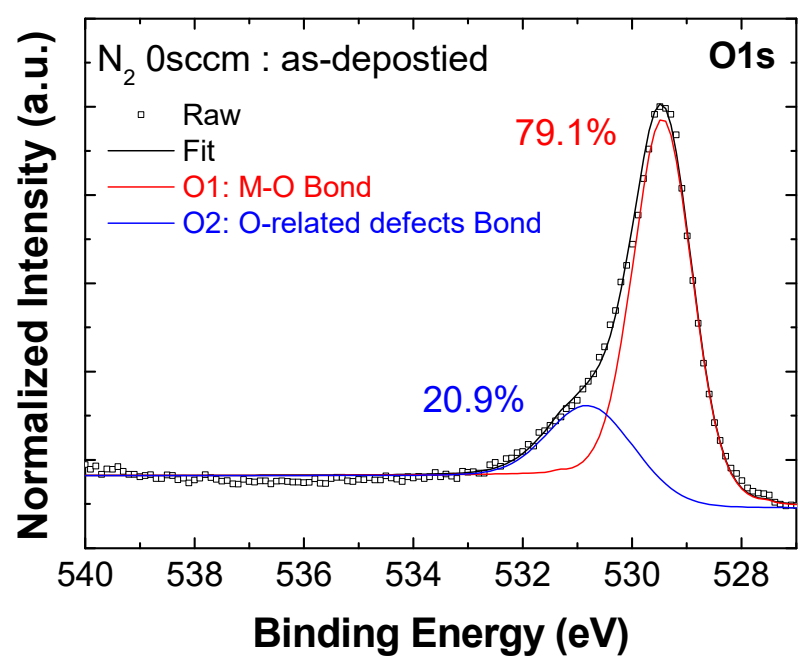

(a)

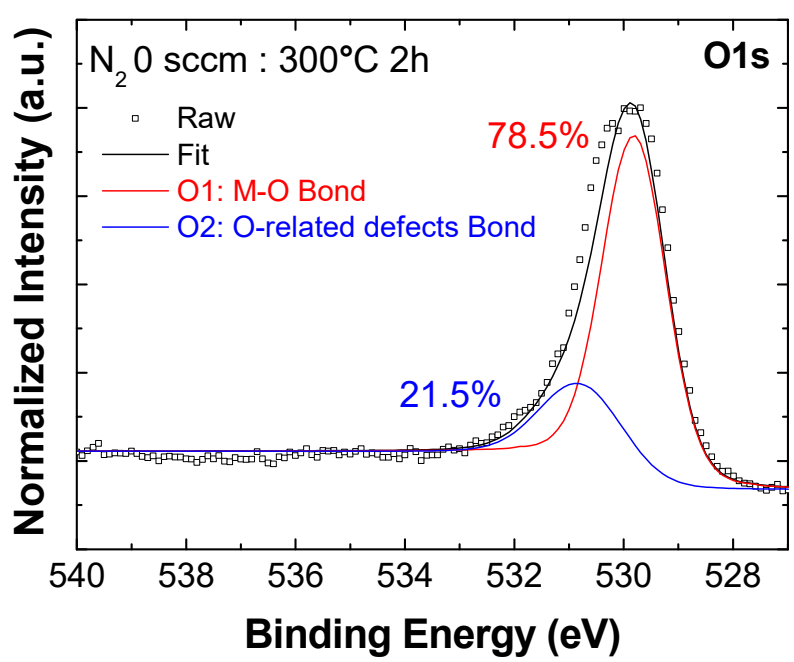

(b)

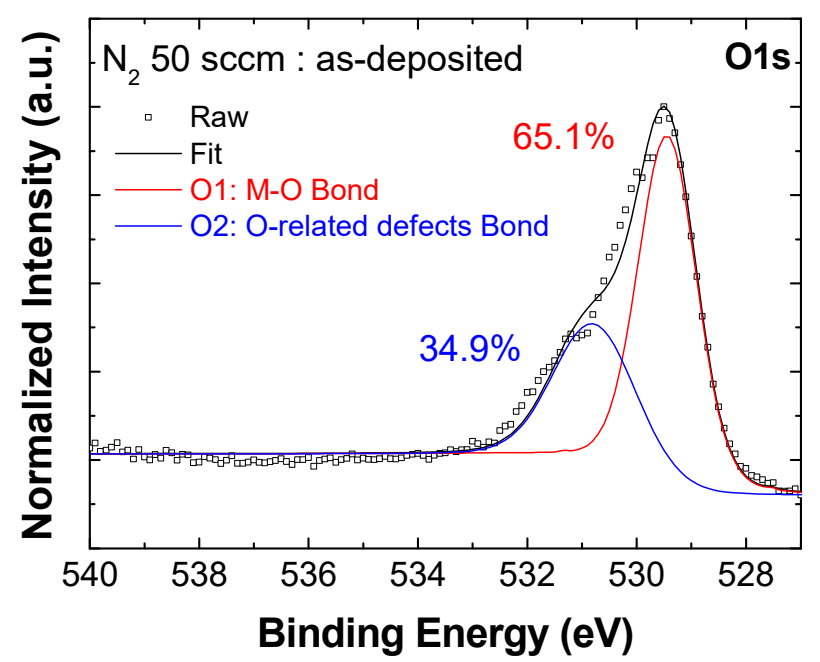

(c)

Figure 5. Cont. 


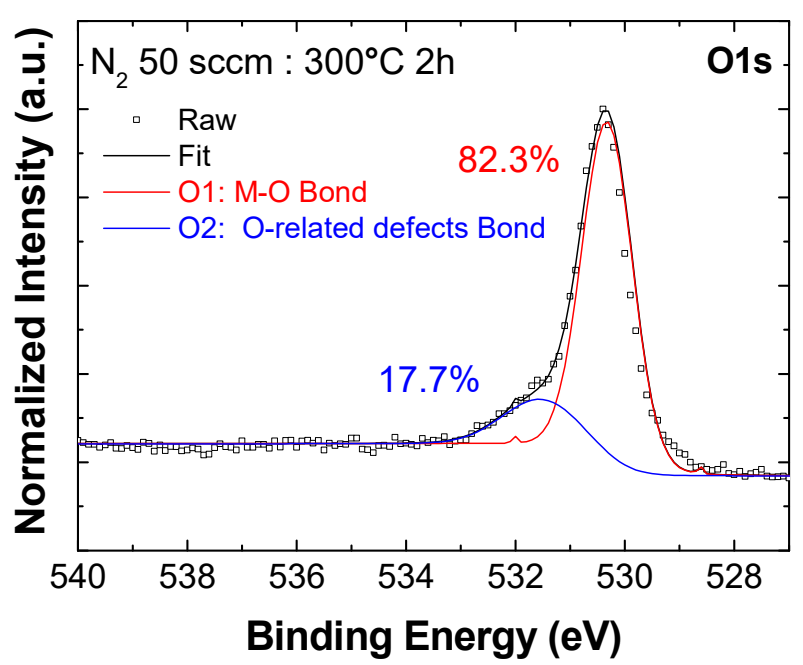

(d)

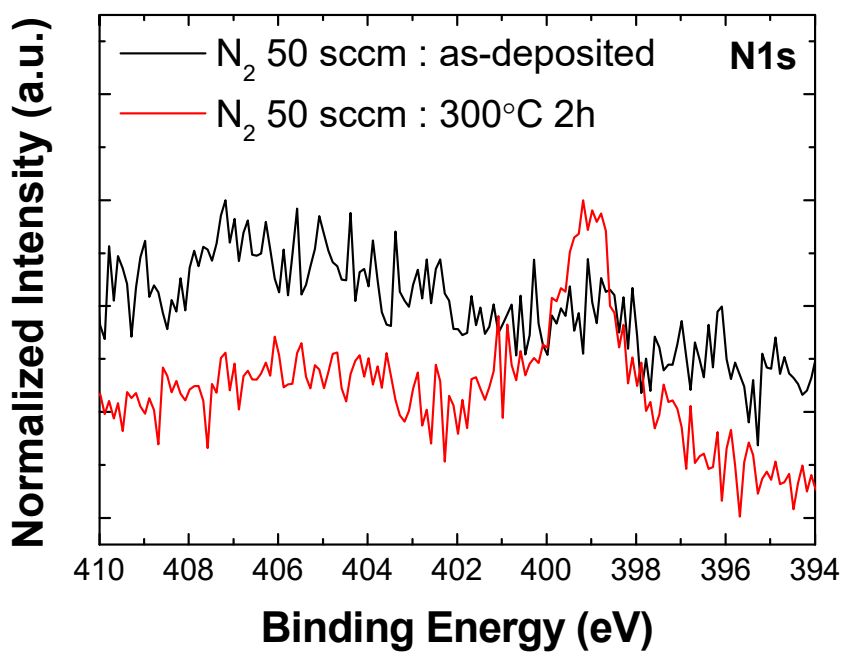

(e)

Figure 5. XPS O 1s peaks of (a) as-deposited $\mathrm{Cu}_{x} \mathrm{O},(\mathbf{b})$ annealed $\mathrm{Cu}_{\mathrm{x}} \mathrm{O}$, (c) as-deposited $\mathrm{CuON}$, and (d) annealed $\mathrm{CuON}$. (e) XPS N 1s spectra of as-deposited $\mathrm{CuON}$ and annealed $\mathrm{CuON}$.

Table 2 shows the Hall measurement results of $\mathrm{Cu}_{\mathrm{x}} \mathrm{O}$ and $\mathrm{CuON}$ thin films, which exhibited p-type behavior. As the nitrogen flow rate is increased during $\mathrm{CuON}$ growth, the carrier concentration values decrease from $2.24 \times 10^{20}$ to $3.59 \times 10^{14} / \mathrm{cm}^{3}$, whereas the Hall mobility increases from 0.33 to $49.8 \mathrm{~cm}^{2} / \mathrm{Vs}$. Generally, $\mathrm{Cu}_{2} \mathrm{O}$ exhibits relatively higher hole transport properties than $\mathrm{CuO}$, even at relatively low carrier concentrations. Here, the increasing Hall mobility may be attributed to the presence of nitrogen, which helps to maintain the $\mathrm{Cu}_{2} \mathrm{O}$ phase.

Table 2. Hall measurement results of $\mathrm{CuON}$ films grown at various $\mathrm{N}_{2}$ flow rates.

\begin{tabular}{ccc}
\hline $\left.\mathbf{N}_{\mathbf{2}} \mathbf{( s c c m}\right)$ & Carrier Concentration $\left(\mathrm{cm}^{-3}\right)$ & Hall Mobility $\left(\mathrm{cm}^{\mathbf{2}} / \mathbf{V} \cdot \mathbf{s}\right)$ \\
\hline 0 & $2.24 \times 10^{20}$ & 0.33 \\
10 & $9.86 \times 10^{16}$ & 4.09 \\
20 & $1.49 \times 10^{15}$ & 32.2 \\
50 & $3.59 \times 10^{14}$ & 49.8 \\
\hline
\end{tabular}


Figure 6a shows the transfer curves of $\mathrm{Cu}_{\mathrm{x}} \mathrm{O}$ and $\mathrm{CuON}$ TFTs with an optimized channel layer thickness at $10 \mathrm{~nm}$. The gate-to-source voltage $\left(\mathrm{V}_{\mathrm{GS}}\right)$ is measured in the range of -30 to $30 \mathrm{~V}$, and the drain-to-source voltage $\left(\mathrm{V}_{\mathrm{DS}}\right)$ is fixed at $-30 \mathrm{~V}$. The conductive characteristics of $\mathrm{Cu}_{\mathrm{x}} \mathrm{O}$ TFTs may be explained by the relatively high carrier concentration. The on-off current ratio and the field effect mobility of $\mathrm{Cu}_{\mathrm{x}} \mathrm{O}$ TFTs are 1.5 and $2.7 \times 10^{-4} \mathrm{~cm}^{2} / \mathrm{Vs}$, respectively. In contrast, the CuON TFTs show improved switching characteristics, with an on-off current ratio and field effect mobility of 7.4 and $6.93 \times 10^{-3} \mathrm{~cm}^{2} / \mathrm{Vs}$, respectively. It is highly anticipated that N 2p orbitals may further enhance the delocalization and hybridization of valence band states, which would enhance the p-type transport properties. $\mathrm{Cu}_{\mathrm{x}} \mathrm{O}$ and $\mathrm{CuON}$ TFTs have poor electrical properties due to the charge trap density between the active layer and the dielectric [19]. The output curve characteristics of the $\mathrm{Cu}_{\mathrm{x}} \mathrm{O}$ and $\mathrm{CuON}$ TFTs are shown in Figure $6 \mathrm{~b}$. While only linear properties are observed in the $\mathrm{Cu}_{\mathrm{x}} \mathrm{O}$ TFT, the $\mathrm{CuON}$ device exhibits clear pinch-off and current saturation without current crowding.

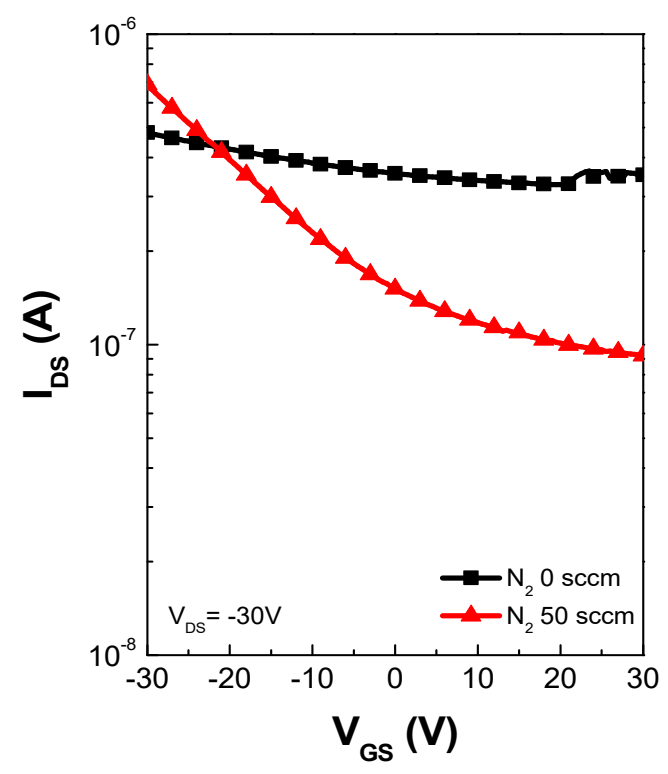

(a)

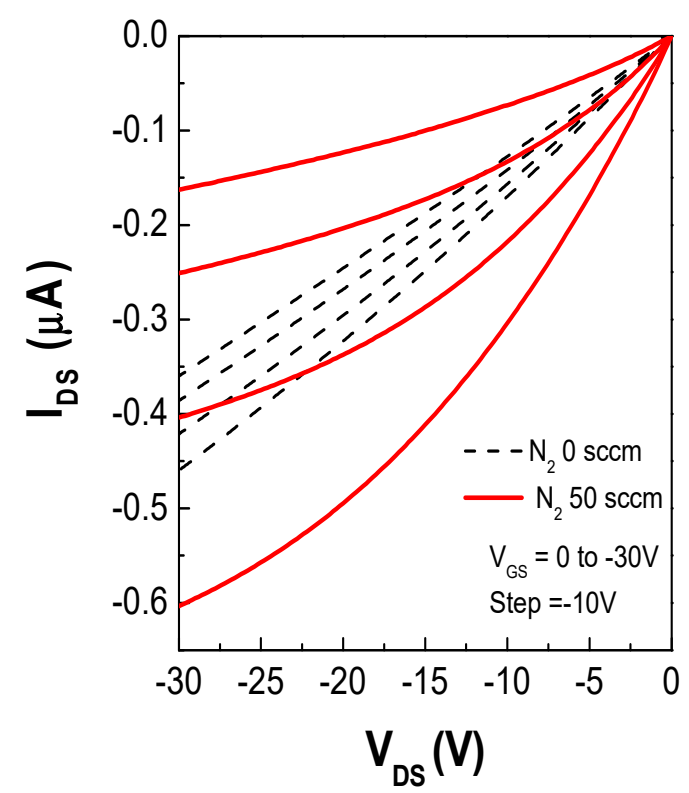

(b)

Figure 6. (a) Characteristics of $\mathrm{Cu}_{\mathrm{x}} \mathrm{O}$ and thin-film transistors (TFTs) transfer curve according to $\mathrm{N}_{2}$ flow rates. (b) Output curves of the $\mathrm{Cu}_{\mathrm{x}} \mathrm{O}$ and $\mathrm{CuON}$ TFTs.

\section{Conclusions}

In the present work, the properties of $\mathrm{CuO}$ and $\mathrm{CuON}$ thin films and the related TFTs were investigated. Structural and chemical analyses indicate that the incorporation of nitrogen promotes the formation of the $\mathrm{Cu}_{2} \mathrm{O}$ phase. In the transmittance spectra, relatively small band tail states are observed in $\mathrm{CuON}$ compared to $\mathrm{Cu}_{\mathrm{x}} \mathrm{O}$, indicating that $\mathrm{CuON}$ is less defective. Also, $\mathrm{CuON}$ films exhibit higher hole mobility than pristine $\mathrm{Cu}_{\mathrm{x}} \mathrm{O}$. Such electrical characteristics are also reflected in the transfer and output curves of the corresponding TFT devices. The above results indicate that the nitrogen incorporation is an effective method not only to obtain a stable $\mathrm{Cu}_{2} \mathrm{O}$ structure, but also to enhance the p-type charge transport properties.

Author Contributions: S.-Y.A. performed the experimental work, analyzed data and wrote the paper; XPS measurement was performed by D.C.; K.P. assisted with XPS data analysis; J.P. and Y.J.K. assisted with writing and editing the paper; H.-S.K., supervised this work.

Funding: This work was supported by Basic Science Research Program through the National Research Foundation of Korea (NRF) funded by the Ministry of Education (Grant No: NRF-2019R1I1A2A01064153) and partially by the MOTIE (Ministry of Trade, Industry \& Energy (Grant 10051403)) and KDRC (Korea Display Research Corporation) support program for the development of future devices technology for display industry. 
Acknowledgments: The authors would like to thank Kim, H.D. and Jang, S.C. for supporting this study.

Conflicts of Interest: The authors declare no conflict of interest.

\section{References}

1. Yang, D.G.; Kim, H.D.; Kim, J.H.; Park, G.; Kim, J.H.; Kim, Y.J.; Park, J.; Kim, H.S. Performance and stability of amorphous In-Ga-Zn-O thin film transistors involving gate insulators synthesized at low temperatures. J. Alloy. Compd. 2017, 729, 1195-1200. [CrossRef]

2. Jang, S.C.; Park, J.; Kim, H.D.; Hong, H.; Chung, K.B.; Kim, Y.J.; Kim, H.S. Low temperature activation of amorphous In-Ga-Zn-O semiconductors using microwave and e-beam radiation, and the associated thin films transistor properties. AIP Adv. 2019, 9, 025204. [CrossRef]

3. Yu, J.; Liu, G.; Liu, A.; Meng, Y.; Shin, B.; Shan, F. Solution-processed p-type copper oxide thin-film transistors fabricated by using one-step vacuum annealing technique. J. Mater. Chem. C 2015, 3, 9509-9513. [CrossRef]

4. Matsuzaki, K.; Nomura, K.; Yanagi, H.; Kamiya, T.; Hirano, M.; Hosono, H. Epitaxial growth of high mobility $\mathrm{Cu}_{2} \mathrm{O}$ thin films and application to p-channel thin films transistor. Appl. Phys. Lett. 2008, 93, 202107. [CrossRef]

5. Figueiredo, V.; Elangovan, E.; Barros, R.; Pinto, J.V.; Busani, T.; Martins, R.; Fortunato, E. p-type Cu $\mathrm{u}_{\mathrm{x}} \mathrm{O}$ Films Deposited at Room Temperature for Thin-Film Transistors. J. Disp. Technol. 2012, 8, 41-47. [CrossRef]

6. Sung, S.Y.; Kim, S.Y.; Jo, K.M.; Lee, J.H.; Kim, J.J.; Kim, S.G.; Chai, K.H.; Pearton, S.J.; Norton, D.P.; Heo, Y.W. Fabrication of p-channel thin-film transistors using $\mathrm{CuO}$ active layers deposited at low temperature. Appl. Phys. Lett. 2010, 97, 222109. [CrossRef]

7. Sohn, J.; Song, S.H.; Nam, D.Y.; Cho, I.T.; Cho, E.S.; Lee, J.H.; Kwon, H.I. Semicond. Effects of vacuum annealing on the optical and electrical properties of p-type copper-oxide thin-film transistors. Sci. Technol. 2013, 28, 015005.

8. Sanal, K.C.; Vikas, L.S.; Jayaraj, M.K. Room temperature deposited transparent p-channel CuO thin film transistors. Appl. Surf. Sci. 2014, 297, 153-157. [CrossRef]

9. Barreca, D.; Comini, E.; Gasparotto, A.; Maccato, C.; Sada, C.; Sbervegloeri, G.; Tondello, E. Chemical vapor deposition of copper oxide films and entangled quasi-1D nanoarchitectures as innovative gas sensors. Sens. Actuator B Chem. 2009, 141, 270-275. [CrossRef]

10. Jang, J.; Chung, S.; Kang, H.; Subramanian, V. P-type $\mathrm{CuO}$ and $\mathrm{Cu}_{2} \mathrm{O}$ transistors derived from a sol-gel copper (II) acetate monohydrate precursor. Thin Solid Films 2016, 600, 157-161. [CrossRef]

11. Kim, S.Y.; Ahn, C.H.; Lee, J.H.; Kwon, Y.H.; Hwang, S.; Lee, J.Y.; Cho, H.Y. p-Channel Oxide Thin Film Transistors Using Solution-Processed Copper Oxide. ACS Appl. Mater. Interfaces 2013, 5, 2417-2421. [CrossRef]

12. Zou, X.; Fang, G.F.; Yuan, L.; Li, M.; Guan, W.; Zhao, X. Top-Gate Low-Threshold Voltage p-Cu 2 O Thin-Film Transistor Grown on $\mathrm{SiO}_{2} / \mathrm{Si}$ Substrate Using a High-k HfON Gate Dielectric. IEEE Electron Device Lett. 2010, 31, 827-829.

13. Refea, M.A.; Roushdy, N. Determination of the optical band gap for amorphous and nanocrystalline copper oxide thin films prepared by SILAR technique. J. Phys. D Appl. Phys. 2009, 42, 015413. [CrossRef]

14. Han, S.; Flewitt, A.J. The origin of the High Off-State Current in p-Type $\mathrm{Cu}_{2} \mathrm{O}$ Thin Film Transistors. IEEE Electron Device Lett. 2017, 38, 1394-1397. [CrossRef]

15. Fortunato, E.; Figueiredo, V.; Barquinha, P.; Elamurugu, E.; Barros, R.; Goncalves, G.; Park, S.H.; Hwang, C.S.; Martins, R. Thin-film transistors based on p-type $\mathrm{Cu}_{2} \mathrm{O}$ thin films produced at room temperature. Appl. Phys. Lett. 2010, 96, 239902. [CrossRef]

16. Jun, T.; Kim, J.; Sasase, M.; Hosono, H. Material Design of p-Type Transparent Amorphous Semiconductor, Cu-Sn-I. Adv. Mater. 2018, 30, 1706573. [CrossRef] [PubMed]

17. Han, S.; Niang, K.M.; Rughoobir, G.; Flewitt, A.J. Effects of post-deposition vacuum annealing on film characteristics of $\mathrm{p}$-type $\mathrm{Cu}_{2} \mathrm{O}$ and its impact on thin film transistor characteristics. Appl. Phys. Lett. 2016, 109, 173502. [CrossRef]

18. Nam, D.W.; Cho, I.T.; Lee, J.H.; Cho, E.S.; Sohn, J.; Song, S.H.; Kwon, K.I. Active layer thickness effects on the structural and electrical properties of p-type $\mathrm{Cu}_{2} \mathrm{O}$ thin-film transistors. J. Vac. Sci. Technol. B 2012, 30, 060605. [CrossRef] 
19. Yang, Y.; Yang, J.; Yin, W.; Huang, F.; Cui, A.; Zhang, D.; Li, W.; Hu, Z.; Chu, J. Annealing time modulated the film microstructures and electrical properties of P-type CuO field effect transistors. Appl. Surf. Sci. 2019, 481, 632-636. [CrossRef]

20. Shijeesh, M.R.; Jayaraj, M.K. Low temperature fabrication of $\mathrm{Cu}_{\mathrm{x}} \mathrm{O}$ thin-film transistors and investigation on the origin of low field effect mobility. J. Appl. Phys. 2018, 123, 161538. [CrossRef]

21. Nakano, Y.; Saeki, S.S.; Morikawa, T. Optical bandgap widening of p-type $\mathrm{Cu}_{2} \mathrm{O}$ films by nitrogen doping. Appl. Phys. Lett. 2009, 94, 022111. [CrossRef]

22. Li, H.J.; Pu, C.Y.; Ma, C.Y.; Li, S.; Dong, W.J.; Bao, S.Y.; Zhang, Q.Y. Growth behavior and optical properties of $\mathrm{N}$-doped $\mathrm{Cu}_{2} \mathrm{O}$ films. Thin Solid Films 2011, 520, 212-216. [CrossRef]

23. Wang, Z.; Al-Jawhari, H.A.; Nayak, P.K.; Caraveo-Frescas, J.A.; Wei, N.; Hedhili, M.N.; Alshareef, H.N. Low Temperature Processed Complementary Metal Oxide Semiconductor (CMOS) Device by Oxidation Effect from Capping Layer. Sci. Rep. 2015, 5, 9617. [CrossRef] [PubMed]

24. Akgul, F.A.; Akgul, G.; Yildirim, N.; Unalan, H.E.; Turan, R. Influence of thermal annealing on microstructural, morphological, optical properties and surface electronic structure of copper oxide thin films. Mater. Chem. Phys. 2014, 147, 987-995. [CrossRef]

25. Jin, Z.; Liu, C.; Qi, K.; Cui, X. Photo-reduced $\mathrm{Cu} / \mathrm{CuO}$ nanoclusters on $\mathrm{TiO}_{2}$, nanotube arrays as highly efficient and reusable catalyst. Sci. Rep. 2017, 7, 39695. [CrossRef]

26. Zhnag, D.; Hu, B.; Guan, D.; Luo, Z. Essential roles of defects in pure graphene/ $\mathrm{Cu}_{2} \mathrm{O}$ photocatalyst. Catal. Commun. 2016, 76, 7-12.

(C) 2019 by the authors. Licensee MDPI, Basel, Switzerland. This article is an open access article distributed under the terms and conditions of the Creative Commons Attribution (CC BY) license (http://creativecommons.org/licenses/by/4.0/). 